\title{
How Creative Processes Are Adapting To Change The World
}

Adaptación de los procesos creativos para cambiar el mundo

Christy Dena, SAE Creative Media Institute - christy@christydena.com

\section{Abstract}

Discourses around standardization and identity formation forestall alternative approaches to creative practice. Changes do happen, however, through pervasive attitudinal shifts articulated in rhetoric. Drawing on the social science research into economic history and choice-based cultural evolution, this essay discusses changes to the notion of conflict and closure in the creative industries. These changes are argued to be provoked by the idea of a choice-based coevolution, that is echoed by many in discourses surrounding practice.

\section{Keywords}

Storytelling, game design, entertainment, rhetoric, culture, evolution.

Sumario

1. Introducción. 2. Methodology. 3. The Obstacles to Change. 4. How Rhetoric Changes Industry, and Creative Processes. 5. Changes to Creative Processes. 6. Conclusions. 7. Bibliography. 


\section{Introduction}

On Friday June the 20th 1975, Steven Spielberg's feature film Jaws opened for the first time in cinemas across America. The giant white shark thriller went on to become the first summer blockbuster, popularised the "high-concept" film, and gave us many scared moments around pools (and for me even just my bedroom floor). For the 40th Anniversary of the film, the Alamo Drafthouse Cinema held a special "Jaws on the Water" event - a screening experience where you watch the film, terrified, on an innertube on the water. Around the same time, Dr Christopher Neff at the University of Sydney released his diachronic study of the Western Australian Government's shark hunt policies (Neff 2014). He found that the policies around hunting sharks were heavily influenced by the man-eating narrative of the film. Government officials were so terrified they made policy decisions to assuage that fear. Films, games, theatre, and TV are all classified as "hedonistic" as opposed "utility" products, in that they are there for sensory pleasures (Hirschman \& Holbrook 1982). But their hedonistic role can mask the important function they play in understanding ourselves and the world. Entertainment can affect the world.

Juxtapose this perspective with what is currently (at the time of writing this introduction) happening in the press and online discussions: the Harvey Weinstein revelations. From the large-scale and very public exposés, there have emerged industrial impacts such as the recognition of the systemic effects of blacklisting women who reject sexual advances in the film industry (Rubin 2017), the unveiling of an Anti-Sexual Harassment Commission in Hollywood (Sun 2017), and the launch of a startup, Rotten Apples, that tracks films that have sexual misconduct accusations associated with them (Desta 2017). Movies affect the world, and the world affects movies. Life and art and commerce are not distinct.

In this essay, I document how the entertainment industries are changing their creative processes towards choice-based coevolution. There have always been people who strive to create not just ethical and meaningful projects, but also engage in ethical and meaningful processes. The former cannot be truly influential without the latter. But the interest in changing creative processes is increasing, in a large part due to the rhetoric surrounding creative industries and beyond. There is a growing concern not just making projects that can affect people in positive ways, but also with the processes undertaken to produce these works.

In what follows is discussion about the impediments to change in the creative industries, how large-scale change happens, and a discussion of two areas where development processes are undergoing transformations in film, TV, digital and games. This includes governing principles of scripts and mechanics alike, their structures, and audience appeal. These are a snapshot of some of the changes happening, but point to very clear paths being laid out for creatives to pursue choice-based cultural evolution in themselves, their processes, and the world.

\section{Methodology}

The research informing this essay is led by the desire to understand societal and creative problems alike. Just as a game developer uses iterative design to understand the nature of problems, as an action researcher I understand through the active production of creative projects, literature reviews, interviews, prototype testing, and blind-testing. I practice both in-reflection and on-reflection activities. I undertake discourse analysis of industry texts (manuals, handbooks, articles, interviews, talks, press) along with online fan discussions, and draw on studies from social sciences, economic history, screenwriting history, narrative studies, and game studies. The less acknowledged aspects of my investigations include introspection, where I observe my own thoughts in my own decision-making processes for choosing and experiencing entertainment; along with naturalistic observation, non-expert and expert interviews.

\section{The Obstacles to Change}

There are at least two factors that thwart change in creative processes: standardization and identity formation. This section will discuss how both of these operate to forestall cultural adaptation in creative industries (and any non-industrial settings). The discourses undertaken in the contexts of standardization and identity formation present a closed logic that have the effect of being anti-pluralist.

Standardization emerges as a solution to a problem. In the context of the desire for commercial and critical success, coupled with the high-cost risks involved with production, it makes sense for standardization practices emerge. They point to a way a project can have the best chance of succeeding. But the flow-on effect is that the belief in the power of standardization as risk mitigation is so pronounced it becomes an unquestionable truth. They become conventional wisdom, nullifying "alternate" approaches. As media theorist Steven Maras explains in his analysis of screenwriting history:

A key problem in screenwriting discourse has to do with thinking about a variety of approaches to screenwriting and scripting. A pluralist approach to screenwriting, one that recognises different styles of scripting, can be difficult to imagine when the dominant focus is on rules for storytelling, proper construction and norms for writing (Maras 2009: 170).

The pushback against different ideas is often due to the belief that those ideas will reduce the effectiveness of the project. Indeed, in his pivotal book Save the Cat!: The Last Book on Screenwriting You'll Ever Need, Blake Snyder wrote about what he calls "the immutable laws of screenplay physics" (Snyder 2005: 119). Snyder explains that "screenwriting is a science as much as an art," and the "rules that govern it are constants, and in some cases eternal (see Joseph Campbell)" (ibid.). Snyder believes that these practices are standard because they are universal laws that will always work throughout time. It is hard to propose alternative approaches, especially as a minority, when creative techniques are presented as immutable and eternal. But what is even more questionable is the claim that screenwriting has found its ideal form in the 100 years since its emergence. Certainty and authority are rhetorical devices in practitioner discourse, but it comes at a cost. Indeed, this is the language of creatives who argue for character transformation on the screen, but the ossification of processes off the screen. So standardization practices, and the gravatas of the accompanying discourse surrounding it, creates an environment in which change is a fool's proposition. 
There is another factor to consider in the pushback against, what Maras calls, a pluralist approach and that is the investment in identification with a particular practice. As a multidisciplinary creative myself, the pushback against those that attempt to be good at more than one thing is tangible. But here I want to highlight more the identification with a specific definition of creative product. This thinking is observable in the furrowed brows of those claiming "that isn't a story" or "that's not a game". These denouncements emerge because of the investment put into differentiating the object or phenomenon of contention and the recognition that comes from being associated with it.

To elaborate, when something perceptibly new comes along, the default approach to identify it as a new phenomenon, or product, is anti-historical. That is, we understand what it is through rejecting similarity to what has come before and then idolising everything that is left. For instance, industry discussions invoked include: games are not stories (Bogost 2017), VR isn't film (Murray 2016), transmedia isn't adaptation (Jenkins 2009). This has had detrimental effects, as has been argued in the context of games practice and scholarship (Golding 2013) where story has been deemed extraneous to best practice (Dena 2017); and in transmedia practice and scholarship where all stories must continue and never adapt across media (Dena 2018).

These anti-historical definitions of a practice help newcomers to recognise difference, provide a practitioner affinity group, and enable potential new economic benefits. In order to protect the new proposition and all that comes with it, boundary policing often occurs publicly and interpersonally, making it a high-stakes proposition to do anything different. Boundary policing is enacted through scholarship, policies, industry texts and talks, curriculum, journalism, and everyday conversations. In such an environment, creatives with alternate ideas may feel that public contrariness will jeopardize their standing and income.

Further to this, when areas of practice are excluded through these new framings, the result is a narrow understanding of what is put at arm's length. Creatives then rely on what education researcher James Paul Gee calls "external design grammars" (Gee 2003). This refers to the knowledge accessible to those external to the design practice: "the principles and patterns in terms of which one can recognize what is and what is not acceptable or typical social practice and identity in regard to the affinity group associated with a semiotic domain" (ibid.: 30 ). In other words, when creatives in games consider story a non-desirable skill, they rely on the guidance of texts that reach beyond their practice domain. The authority and certainty of Aristotle, Campbell, and McKee, all then become the rules in another artform.

In summary, two factors that work to suppress change in the creative processes are the standardization practices and identity formation, and their accompanying reinforcing discourses. The authority, confidence, pervasiveness, and seeming immutability of these views renders alternative view outsider behaviour. However, it is the power of discourses that can also successfully counter these rigidities. The next section will explore how changes can happen in creative processes.

\section{How Rhetoric Changes Industry, and Creative Processes}

How does change happen? There are theories and processes around habit change, perspective shifts, and transformational learning. But here the discussion is about large-scale change. How does an industry, indeed, many entertainment industries undergo change? This section discusses a compelling proposition from social science and economic history, that of the rhetoric of people with a shared attitudinal shift. To begin, we will look at ways creatives are calling for a conscious approach to change.

As a practitioner, I know the effect processes, tools, and methods have on production and output. But standardization and identity formation policing creates an environment where we don't feel things can change. Script formats, plot structures, and mechanics all seem immutable in the face of conventional wisdom and economic viability. Even though these conventions were introduced as a reaction to previous paradigms, it seems that the task of progression is complete. But, as designers, researchers, and educators Anthony Dunne and Fiona Raby argue:

The world we live in today is incredibly complex, our social relations, desires, fantasies, hopes and fears are very different from those at the beginning of the 20c. Yet many key ideas informing mainstream design stem form the early 20c. Society has moved on but design has not, Critical Design is one of many mutations design is undergoing in an effort to remain relevant to the complex technological, political, economic and social changes we are experiencing at the beginning of the 21c (Dunne \& Raby 2011).

For Dunne and Raby, progression can happen through Critical Design — which is about making a conscious effort to critique society but also the creative systems that produce our creative work. Likewise, designer Thomas Wendt calls for a Cunning Design Practice:

Cunning design practice is a loose strategy for understanding how to design away neoliberal passivity and get folks organized against common enemies of the people. The rationalism that ruled the last few centuries will not suffice to deal with the complexity of the coming age. It sounds trite, as it is said at the start of every era, but we simply cannot rely on old modes of thinking to design our way out of such a complex situation. Complexity calls for cunning (Wendt 2017: 183).

Underlying these manifestos is the message: things will not get better by themselves. Action has to be taken. Creatives can make changes as individuals, and these can impact their team members, stakeholders, and those touched by knowledge sharing. But how does bigger change happen, in the area of "Consensual Big-C Creativity" (Kaufman \& Beghetto 2009, Simonton 1994) and beyond, especially in the face of strict beliefs around what enables commercial success? For instance, how can there be a greater range of gender representation when there is an ingrained belief that only male actors sell films? How can there be a range of interaction modes when there is the ingrained belief that competitive mechanics are the best way to sell games? While there are many factors involved in large-scale change, there is one factor I wish to highlight here: the role of rhetoric in cultural evolution.

Over the last decade, there has been a seismic shift taking place with economic historians. There is a consensus, of course, that since 1800 our world has transformed economically with the majority of the world richer than it was before. What economists have not been clear about is why this happened. Ask any person on the street, and they will tell you that the way to make money is through the machinations of capitalism. You need goods, services, demand, market competition, and so on. This is the belief that drives many industries, including the creative industries. But the 
economists have crunched the numbers and they don't add up. It turns out that bricks and billions are not the trick to wealth. None of the traditionally-conceived notions of capitalistic mechanisms, specifically accumulation, are enough to explain the massive changes. Instead, it is a change in "ideas," in "attitudes," articulated through the "rhetoric" of creatives and intellectuals and beyond.

The key champion of this insight is Deirdre McCloskey. McCloskey's formidable trilogy, (presently) ending with Bourgeois Equality: How Ideas, Not Capital or Institutions, Enriched the World, documents in great detail how and why "the world bec[a]me dramatically richer in the two centuries after 1800" (2016: 151). Specifically, it was "not material causes" but instead "the rhetoric and implementation of ethics" that affected "trade-tested betterment" (ibid.). According to McCloskey and an increasing amount of economic historians, accumulation by itself does not account for wealth creation. Accumulation by itself is "greed," and McCloskey invokes comedian George Carlin to explain that greed is "bullshit and it's bad for you" (McCloskey 2011). Instead, other virtues, and specifically the idea of "equal dignity" is the pervasive idea articulated in creative projects, scholarship, discourses, that drove economic change.

McCloskey is not alone, with economists such as Joel Mokyr presenting his own take with notion of ideas influencing economics. For Mokyr, ideas and rhetoric are reframed through the social science area of "choice-based cultural evolution" where "adults make cultural choices about religion, social relations, political beliefs, the value of time, material consumption, and anything else" (Mokyr 2017: 34). This is an area of investigation, where evolution is not seen through purely through genetic factors, but instead through cultural factors. How do people change because of the cultures around them? Many studies look at children, and how "preferences of children are acquired through an adaptation and imitation process which depends on their parents' socialization actions, and on the cultural and social environment in which children live" (Bison \& Verdier 2001: 299). Specifically, this research area looks at cultural transmission, through parents, and social role models, and also media. On the latter, researchers have looked at changing attitudes to smoking, for and against, in light of parents and strategic industry campaigns (Christopoulou, Jaber \& Lillard 2013).

For Mokyr, rather than look at children and smoking, his object of study is technological shifts. A key cultural change he has identified is a shift in "attitude toward Nature" and how this has affected the growth and direction of technology (Mokyr 2017: 14). An industrial articulation of this attitude shift can be seen in serial entrepreneur John Elkington's "Triple Bottom Line" (1997). This is where companies can track the full cost of doing business through addressing the "3 Ps" of profit, people, and the planet.

Cultural transmission affects people, and choice-based coevolution is the conscious effort to change yourself and others. Taking these insights into this context, what are the ideas influencing creative processes now? It is my contention that changes to creative processes are increasing, and they are in large part doing so because of the rhetoric circling the world. Even though putting forward new propositions through creative projects, online discussions, papers, presentations, and the press can feel like a blunt instrument in the face of deeply ingrained biases, systemic prejudices and ossified infrastructures, transformations are happening.

A key recurring theme I am seeing from audience behaviours, project themes, industrial and everyday discourses, and process reformations is choice-based coevolution. From makeover reality shows, self-help books, perspective-changing documentaries, participatory culture, persuasive technology, open source approaches, biomimicry, artificial intelligence, mixed reality, emergent systems, and beyond, the world is humming to the idea of conscious creation and the responsibility that comes with it. That is: we can change things, we can make the choice to evolve, and we do that because we perceive we're not the only ones wanting and doing this. In creative practice, this manifests as changes to the themes of projects, the nature of creative projects, the processes to create them, and the people involved. In what follows, I document some of the ways changes to creative processes are echoing this idea.

\section{Changes to Creative Processes}

What are the changes happening to creative processes, and how do they relate to the notion of choice-based coevolution? While there are many areas to draw on, the two areas of change in creative processes highlighted here are the interdisciplinary concepts of conflict and closure. In what follows, I discuss the discourses against and for change, and how both affect our perception of the world.

\subsection{Beyond Conflict}

One of the prevalent ideas in entertainment discourse is that of "conflict". Stories, scripts, and games must have conflict. Robert McKee, a bestselling story consultant and educator, regards conflict as a "Law" (McKee 1999: 210). "When a protagonist steps out of the Inciting Incident," McKee explains, "he enters a world governed by the Law of Conflict. To wit: Nothing moves forward in a story except through conflict. Put another way, conflict is to storytelling what sound is to music" (ibid., original emphasis). There is such gravatas in the language that an alternate scenario would not emerge in the reader's mind. Furthermore, McKee goes on to explain how this trait, conflict, is a trait of life:

The Law of Conflict is more than an aesthetic principle; it is the soul of story. Story is metaphor for life, and to be alive is to be in seemingly perpetual conflict. As Jean-Paul Sartre expressed it, the essence of reality is scarcity, a universal and eternal lacking. There isn't enough of anything in the world to go around. Not enough food, not enough love, not enough justice, and never enough time (ibid.: 211).

To McKee, conflict as a key trait of stories makes sense because it is a key trait of (his) life. Interestingly, the language of scarcity, reality of conflict, and eternal lacking are the same terms used by economists to champion capitalism without the ideas, virtues, or ethics that are actually needed to bring progress. Creative structures and processes reflect our ways of seeing the world, and influence how others see the world.

So too in games, "conflict" has been used as part of the definition of what a game is. In his popular The Art of Game Design, Jesse Schell provides an overview of a few definitions of game, often with "conflict" in them (Schell 2010). One of the definitions is from Tracy Fullerton, another author of a popular book: Game Design Workshop (Fullerton 2008). Conflict is a formal element of a game, and like stories, "emerges from the players trying 
to accomplish the goals of the of the game" (ibid.: 77-78). But Fullerton includes in this term different instantiations of conflict: obstacles, opponents, and dilemmas (ibid.).

It is the opponents aspect that has been a long-standing default in creating conflict, and this manifests as competitive play. Mechanics, the actions of the player, are often taught through the lens of a zero-sum game scenario, where the victory of one entails the loss of another. There are no winwin scenarios. Games are interesting, exciting, and successful, when they involve players competing against each other, or the game. Sheri Graner Ray, who has worked on games such as Star Wars Galaxies, Ultima, and Nancy Drew writes that the "concept of conflict as a basis for a game is so deeply entrenched that for the majority of players, it actually defines the term 'game"' (Ray 2004: 40). Ray continues,

At the heart of virtually all traditional computer games is a conflict situation. The 'bad guys' want you dead. The 'enemy' wants to take your land. The 'monsters' have taken control of your cast dungeon. The 'other guy' wants to get to the finish line before you (ibid.: 38).

Conflict is so ingrained that when ideating story and game concepts, the default is to design conflict, often between people. These first thoughts of conflict are often antagonists that are unintelligent, unwise or despicable people, creatures, or robots. These antagonists have a raft of negative personality traits, that are normalised or at least justified. The character went on a killing spree because their parent was murdered when they were a child, or because their wife was raped. Indeed, these are the kinds of motivations we give characters to explain why harm is being done: revenge, anger, greed, lust, stupidity, selfishness, bias (gender, racial, class, sexuality, etc). When you design with these motivations driving action, you create a world logic where people have no grief-coping skills, uncritically project their own self-loathing onto others, are incapable of mediating their self-worth without external validation or gratification, don't look honestly at themselves, aren't prepared to be vulnerable, uncritically go with their infantile instincts, don't forgive, are ungracious, don't learn and change from their experiences, and do not reflect on their own mortality. These dominant character traits make it even harder to imagine a pluralist approach to creative practice, let alone the world.

But despite these ominous Laws, conflict is not the only way to create a great story or game, and certainly not through these negative personality traits. A long time vocal opponent of the notion of "conflict" as an essential element is Raúl Ruiz. Ruiz is a Chilean filmmaker who has made over 100 films, and has argued against the pervasive ideology of the "central conflict" (Ruiz 1995). He describes the conflict beginnings as being baked into the popular dramatic formula of "someone wants something and someone else doesn't want them to have it," and he explains how "[f]rom this point on [...] all the elements of the story are arranged around this central conflict" (ibid.: 11). Ruiz laments the effect of this rule, as it not only influences funding bodies on what to fund and not, but also creates a logic for how the world works:

The voracious appetite displayed by this predatory concept reaches far beyond theory. It has become a normative system. The products which comply with this norm have not only invaded the world but have also imposed their rules on most of the centers of audiovisual production across the planet. [...] And yet there is no strict equivalence between stories of conflict and everyday life" (ibid.: 15).

Ruiz saw conflict as a peculiarly Western construction, and is not alone. A popular post by an art collective "still eating oranges," published 20 years after Ruiz, takes aim:

The necessity of conflict is preached as a kind of dogma by contemporary writers' workshops and Internet "guides" to writing. A plot without conflict is considered dull; some even go so far as to call it impossible. This has influenced not only fiction, but writing in generalarguably even philosophy. Yet, is there any truth to this belief? Does plot necessarily hinge on conflict? No. Such claims are a product of the West's insularity. For countless centuries, Chinese and Japanese writers have used a plot structure that does not have conflict "built in," so to speak. Rather, it relies on exposition and contrast to generate interest. This structure is known as kishøenketsu. (still eating oranges collective 2015)

They continue, explaining how Kishōtenketsu contains four acts: introduction, development, twist and reconciliation. For this structure, the beginning is all about setup, and it isn't until the third act when major changes occur. Those major changes are a surprising element. The final act then reconciles the difference between the setup and surprise to bring them together. These are subtle differences that account for a very different way of seeing plot structure.

In games, Ray highlighted the use of "indirect competition" as a technique to use instead of competition (Ray 2004: 45). There have been many games that utilise this, a recent example being Ubisoft's Child of Light, where there is battle but on distinct cliffs, so there is no direct clashes of your player character(s) and the enemy. The attacks are also turn-based, which means you take turns attacking each other. The commercial and critical success of thatgamecompany's Journey also points to an example of a game that privileges collaboration above competition. The pleasures come not from winning over another, but from the internal obstacles projected onto the allegorical setting.

Indeed, if one considers a healthy version of obstacles that aren't about negative personality traits, it would be the simple flaws and mishaps that happen naturally. Not due to nefarious intent. Steve Kaplan, a comedy writing educator who created the HBO Workspace, the HBO New Writers Program and consults and script doctors to companies such as Dreamworks, Disney, Paramount, and Touchstone, discusses this in his book:

Conflict comes about because any task given to a group of people is going to reveal the strains, crevices, and fault lines in the individuals and their relationships with each other. If you gave three people the same task and asked them to work in perfect harmony with each other, they couldn't do it. At least not well. There'd be differences of opinion, misunderstandings, arguments, efforts at crosspurposes. Because conflict is inherent to the human condition. You don't need to create problems, because a human being is going to have enough trouble doing even the simplest thing. (Kaplan 2013: 45-46)

Examples of stories that don't invoke the negative personality traits for conflict cited earlier include Magic Mike XXL. At the time of writing, the feature sequel is ranked 1,206 in the worldwide box office with an intake of over 123 million (Nash Information Services 2017). The feature film is structured around the journey of Magic Mike and the ensemble dance troupe finding true happiness in being themselves in their work and life. Unlike the previous film, Magic Mike, there is no antagonist. Obstacles are present, in the internal drive to find their new identity, the need for a 
good MC, their hedonistic flaws that result in a car crash, the need to find a car, and potential suited partners. But there is no antagonist with negative personality traits causing conflict in their lives.

Projects and the rhetoric around conflict are changing, and they are accelerating. Jeff Gomez, consultant to franchises such as Pirates of the Caribbean, Avatar, and Halo, laments the prevalence of conflict in screenwriting, "which most often manifests as physical or psychological violence" (Gomez 2017a). But, Gomez continues, "the nature of conflict is changing," and to address this he has proposed an update to the Hero's Journey: The Collective Journey. One of the ideological traits of this structure is the notion that "no-one is coming to save you" (Gomez 2017b). Collective stories, instead, "are about how communities actualize in their attempt to achieve systemic change" (ibid). This actualization is through their own storytelling, not those of the singular hero, or the author or corporation. Once again, the language is of a choice-based evolution, where change is intentionally enacted, by many. Let's continue this exploration by looking at how it manifests in the notion of "closure".

\subsection{Beyond Closure}

In The Screenwriter's Bible, David Trottier quickly takes his readers through the essential basics of story before moving into page formatting. An important point he makes is that in the penultimate moment of your story, you must "bring closure to your story's end; don't leave its ending open or ambiguous" (Trottier 2005: 19). In his book-length critique and exposition of limiting conceptions of games, Brian Upton describes three kinds of agendas players have when it comes to their goals of play (Upton 2015: 195). One of them is "closure-oriented play," which is a "narrativist agenda" where the player perceives the ending when "the needs of the characters have been satisfied and the conflicts implicit in the situation resolved" (ibid.). What does closure mean to the audience experience?

In 2006, I was commissioned to write and design an alternate reality game for an industry lab run by the Australian Film, Television and Radio School. The structure had teams investigating constructed artefacts to unearth different revelations about a murder. I intentionally designed it so each team would uncover a different killer. The finale then involved all the teams coming together to debate who they thought the killer was. At the end, in our post-game debrief, the players asked who the killer was. My co-writer said who she thought the killer way, whereas I did not have one killer in mind. The players felt more relief in knowing a writer, my co-writer, had a specific killer in mind. From this experiment, I discovered how important it was for players to have feedback about how they're going (in this case a hypothesis-confirmation), and how different the equally forkedoutcome approach was. But the disquiet with such a polysemous approach is trained.

Nitzan Ben Shaul outlines this in his book, where he finds "most films encourage a closed state of mind, biasing our cognitive processes toward a reductive and selective attention to incoming data" (Shaul 2015: 1). Writers, he continues, do this because they privilege the emotional pleasures afforded by cognitive reductionism, laud the pleasures of simplicity, or ignore the cognitive effects of their choices. Viewers are taught to seek "hypothesis-confirmation". They are trained to consider possible outcomes, but desire a single one. For instance, with suspense, the key options are that 1) a bad thing happens to a good person, or 2) a bad thing doesn't happen to a good person - the latter of which is the audience desire. Or in an action film, where audiences can calculate four possible outcomes: 1) protagonist lives, antagonist dies (desired outcome); 2) protagonist dies, antagonist lives; 3) protagonist and antagonist dies; or the 4) protagonist and antagonist lives. There is pleasure from imagining the possibilities, but that conclusions must transform to a correct one.

There are films that buck such closure though. In his book about the nature of independent screenplays, J.J. Murphy explains how "Art cinema has always attempted to avoid the maximum clarity and comprehensibility demanded by classical Hollywood cinema by substituting ambiguity in its place" (Murphy 2007: 260). Murphy explains that this "is why a manual writer such as Linda Seger, steeped as she is in conventional paradigm, takes a critical view of this film [Mulholland Dr.]" (ibid.: 205). Citing creators who have bucked conventional structures-Linklater, Jarmusch, haynes, Anders, Korine, Van Sant, July and Buscemi-Murphy argues that adhering to writing manuals "only guarantees that your screenplay will end up being conventional" (ibid.: 266).

Anti-closure is, to Murphy, about ambiguity, about mystery. But what if ambiguity was less about lack of closure due to not having something to grasp onto, and more about there being multiple equally-viable outcomes? This is what Shaul argues. Most films "reduce cognitive activity and block optional thinking in viewers" (Shaul 2015: 114). Optional thinking on the other hand, encourages viewers (and readers and players) to actually find pleasure in more than one probable outcome. Shaul explains how this is encouraged with particular techniques that prevent closed mindedness: alternative narrative tracks \& closures, and perspectives within the fictional world of the movie.

On the former, viewers follow two or three alternative narrative trajectories leading to different closures. This is achieved by giving viewers enough information to construct the alternate narrative tracks in their minds, and those tracks can be compared and assessed due to the use of constants across tracks and divergences stemming from variables (ibid.: 124). For instance, surprises do not negate previous alternate hypothesis, as we see in The Sixth Sense. Whereas in films like Run Lola Run, we watch three consecutive versions of the same event. Each one has the same inciting incident (the phone call) with different outcome: in the first Lola is killed, in the second Manni is killed, and in the third they both get away with the money (happy ending). To facilitate comprehension, the film uses "cohering strategies" by invoking familiarity and variation. There are the same temporal and spatial trajectories, recurrence of some actions, and use of the same characters. By having these similarities, we then can see what the differences are and contrast them; and none of them negate the other.

In Sliding Doors (which it should be noted is an example of a non-art-film using these techniques), the versions are not presented consecutively but instead zig-zag between each other. They both begin with the two versions of the same incident: missing or catching the train. The repetition of the event helps ground the two versions for the viewer. In one version she catches the train, meets a new guy, gets home to find her current boyfriend is cheating on her, and then ends up living happily with the new guy. In the other version, she misses the train and misses finding out about her current boyfriend's infidelity and lives a miserable life with him. We zig-zag between the two lives, with a "good" one happening in the end. But the key here, Shaul explains, is that there is an ending scene where she meets the new guy again. So the inference is that both pathways would have led to a good outcome, rather than one being negated. Both paths work.

Another technique Shaul outlines is character perspectives. This works when empathy for more than the lead protagonist is facilitated by taking each of their respective perspectives. There is the further pleasure then of the different outlooks compelling a reassessment for narrative 
comprehension. An example is Akira Kurosawa's Rashomon, where we experience contradictory versions of the same event through flashbacks of different characters narrated by an unreliable witnesses. We search for the truth in the different accounts, but cannot find it because of the unreliable narrators. So we refocus to a theme of unreliability and subjectivity. (ibid: 135). Ultimately, though, it is not about the loss of truth, but the searching for truth and "the feasibility of choice and change in one's life" (ibid.: 140).

These are likewise the traits lauded in games, where players can take on multiple viewpoints to develop empathy not just for the characters but also for the people they represent in life. Practitioner-researchers Jonathan Belman and Mary Flanagan discuss the use of intentionally taking a person's point of view, "cognitive empathy," in games (Belman \& Flanagan 2009). For instance Impact Games' Peacemaker has two player-character options, that of the Israeli Prime Minister or the Palestinian President. Play involves understanding the complexity of both their own assumed role and its relationship to other stakeholders. Perspective taking for empathy is so much part of the rhetoric of games and interactivity in general, that there has even been pushback to the idea of its effectiveness. Game designer Anna Anthropy made a game in protest, Empathy Game, where you literally walk in Anthropy's shoes. This is part of Anthropy's artistic statement:

Empathy Game is about the farce of using a game as a substitute for education, as a way to claim allyship. You could spend hours pacing in a pair of beaten-up size thirteen heels to gain a point or two - a few people did! - and still know nothing about the experience of being a trans woman, about how to be an ally to them. Being an ally takes work, it requires you to examine your own behavior, it is an ongoing process with no end point. That people are eager to use games as a shortcut to that, and way to feel like they've done the work and excuse themselves from further educating themselves, angers and disgusts me. You don't know what it's like to be me. (Anthropy 2015)

But even in the critique of perspective for empathy, there is the overarching drive towards personal transformation. The concern in both instances, changing perspective and the critique of it, is towards enabling positive transformation. Indeed, moving beyond closure means optional thinking. It means perceiving multiple viable pathways and perspectives. With both and conflict and closure, we've seen how discourses have framed them as immovable processes, but then contrary discourses have been emerging to counter them. The Laws and rules are reflective of an ideology that doesn't recognise choice-based cultural evolution. Who we are is seen as fixed: processes shouldn't change, conflict is a way of life, there are not multiple options, that are not other perspectives. These attitudes affect the way we create, what we create, and how we see the world. But views that see the world as changeable are providing the impetus, insight, and guidance needed to actually change it.

\section{Conclusions}

Well-known writing consultant Michael Hauge explains that the "most powerful and persuasive stories don't simply entertain or enlighten - they challenge their readers and audiences to transform - to find the courage to change their thoughts and behaviors in order to achieve a more fulfilling, loving and self-defined existence" (Hauge 2017). Indeed, any creative project has the potential to transform people. Importantly though, are the subtle messages about the way the world works and whether people have agency in it. In this essay, I have argued that widespread changes are happening to creative processes. These changes are part of an attitudinal shift towards our perception of growth. Drawing on the work of social science studies and economic historians, the notion of cultural transmissions was introduced as a key factor in this change. Through the rhetoric of industry (and non-industry) sources changes are happening in the subject matter of creative projects, the content structures that inform them, the processes that make them, and the people that experience them. This choice-based coevolution means creators are aware of the impact of their tale about a killer shark, know what they're doing when they create the startup Rotten Apples, and understand that "[i]f we're going to be truly disruptive, we have to hold ourselves accountable to what we create" (Kip 2016).

\section{Bibliography}

Anthropy, A. (2015). "Empathy Game." AuntiePixelante, n.d. http://auntiepixelante.com/empathygame/.

Belman, J. \& Flanagan, M. (2009). "Designing Games to Foster Empathy." Cognitive Technology 14(2): 5-15.

Bison, A. \& T. Verdier (2011). "The Economics of Cultural Transmission and the Dynamics of Preferences." Journal of Economic Theory 97: 298319. doi:10.1006jeth.2000.2678.

Bogost, I. (2017). "Video Games Are Better Without Stories." The Atlantic, 25 April. https://www.theatlantic.com/technology/archive/2017/04/videogames-stories/524148/.

Christopoulou, R., Jaber, A., \& D.R. Lillard (2013). "The Inter-Generational and Social Transmission of Cultural Traits: Theory and Evidence From Smoking Behaviour." NBER Working Paper 19304. doi: 10.3386/w19304

Dena, C. (2017). "Finding a Way: Techniques to Avoid Schema Tension in Narrative Design." Transactions of the Digital Games Research Association (ToDiGRA) 3 (1), 27-61. doi: 10.26503/todigra.v3i1.63

Dena, C. (2018). "Transmedia Adaptation: Revising the No-Adaptation Rule." In Freeman, M. and Gambarato, R. The Routledge Companion to Transmedia Studies. New York: Routledge.

Desta, Y. (2017). "Rotten Apples Is Like Rotten Tomatoes with a Post-Weinstein Twist." Vanity Fair, 14 December. https://www.vanityfair.com/hollywood/2017/12/rotten-apples-website-weinstein.

Dunne, A. \& Raby, F. (2011). "Critical Design FAQ." DunneandRaby. http://www.dunneandraby.co.uk/content/bydandr/13/0

Elkington, J. (1997). Cannibals with Forks: The Triple Bottom Line of 21st Century Business. Oxford: Capstone Publishing. 
Fullerton, T. (2008). Game Design Workshop: A Playcentric Approach to Creating Innovative Games, 2nd Edition. Burlington: Morgan Kaufmann. Gee, J.P. (2003). What Video Games have to Teach Us about Learning and Literacy. New York: Palgrave Macmillan.

Golding, D. (2013). "To Configure or to Navigate?: On Textual Frames." In Waggoner, Z. (Ed.) Terms of Play: Essays on Words That Matter in Videogame Theory. Jefferson: McFarland \& Company, Inc.

Gomez, J. (2017a). "When it Comes to Story, You're Not Getting It." Medium, 14 February. https://blog.collectivejourney.com/when-it-comes-tostory-youre-not-getting-it-f6e1f20006f1.

Gomez, J. (2017b). "The Collective Journey Comes to Television." Medium, 18 February. https://blog.collectivejourney.com/the-collective-journeystory-model-comes-to-television-151bb4011ce2.

Haughe, M. (2017). "What's Your Theme." Story Mastery, 8 November. https://www.storymastery.com/character-development/whats-your-theme/ Hirschman, E., \& Holbrook, M. (1982). Hedonic Consumption: Emerging Concepts, Methods and Propositions. Journal of Marketing, 46(3), 92-101. doi:10.2307/1251707

Hindle, T. (2009). "Triple Bottom Line." The Economist, 17 November. http://www.economist.com/node/14301663.

Jenkins, H. (2009). "The Aesthetics of Transmedia: In Response to David Bordwell (Part 1)." Confesssions of an ACA-FAN, 10 September. http://henryjenkins.org/blog/2009/09/the_aesthetics_of_transmedia_i.html.

Kaplan, S. (2013). Hidden Tools of Comedy. CA: Michael Wiese Productions.

Kaufman, J. C., \& Beghetto, R. A. (2009). "Beyond Big and Little: The Four C model of Creativity." Review of General Psychology, 13: 1-13.

Kip. (2016). "Designing an AI Persona." Medium, 19 January. https://medium.com/@kipsearch/designing-an-ai-persona-4a7c123c27ca.

McCloskey, D. (2011). "The Treason Of The Clerisy: Capitalism And The Intellectuals After 1848." Mercatus Center, George Mason University, 24 October. https://www.youtube.com/watch?v=Fh2C47HRDKQ.

McCloskey, D. (2016). Bourgeois Equality: How Ideas, Not Capital or Institutions, Enriched the World. Chicago: University of Chicago Press.

McKee, R. (1999) Story: Substance, Structure, Style, and the Principles of Screenwriting. London: Methuen.

Murphy, J. (2016). "A Film is Not a Film and Not an Empathy Machine." Immerse, 7 October, https://immerse.news/not-a-film-and-not-an-empathymachine-48b63b0eda93.

Nash Information Services. (2017). "Magic Mike XXL." The Numbers (n.d.). https://www.the-numbers.com/movie/Magic-Mike-XXL.

Neff, C. (2014). "The Jaws Effect: How Movie Narratives are Used to Influence Policy Responses to Shark Bites in Western Australia." Australian Journal of Political Science, 1, 114-127. doi: 10.1080/10361146.2014.989385

Ray, S.G. (2004). Gender Inclusive Game Design: Expanding the Market. Hingham: Charles River Media, Inc.

Rubin, R. (2017). "Ashley Judd, Mira Sorvino Respond to Peter Jackson's Claims That Weinstein Blacklisted Them." Variety, 15 December. http://variety.com/2017/film/news/ashley-judd-mira-sorvino-weinstein-blacklist-peter-jackson-1202642211/.

Ruiz, R. (1995). Poetics of Cinema (translated by Brian Holmes). Paris: Dis Voir.

Schell, J. (2010) The Art of Game Design: A Book of Lenses. Burlington: Elsevier.

Schwartz, S. (2011). "Studying Values: Personal Adventure, Future Directions." Journal of Cross-Cultural Psychology, 42(3): 307-19.

Schwartz, S. H. (1992). "Universals in the Content and Structure of Values: Theoretical Advances and Empirical Tests in 20 Countries." In M. P. Zanna (Ed.), Advances in Experimental Social Psychology, 25: 1-65. Orlando: Academic Press.

Shaul, N.B. (2015). Cinema of Choice: Optional Thinking and Narrative Movies. New York: Berghahn.

Simonton, D. K. (1994). Greatness: Who Makes History and Why. New York: Guilford Press.

Snyder, B. (2005). Save the Cat!: The Last Book on Screenwriting You'll Ever Need. Studio City: Michael Wiese Productions.

Still eating oranges collective (2015). "The Significance of Plot Without Conflict." still eating oranges, 15 June. http://stilleatingoranges.tumblr.com/post/25153960313/the-significance-of-plot-without-conflict. 
Sun, R. (2017). "Top Hollywood Execs Unveil Anti-Sexual Harassment Commission Chaired by Anita Hill." The Hollywood Reporter, 15 December. https://www.hollywoodreporter.com/news/top-hollywood-execs-unveil-anti-sexual-harassment-commission-chaired-by-anita-hill-1068646.

Trottier, D. (2005). The Screenwriter's Bible: A Complete Guide to Writing, Formatting, and Selling your Script, 4th Edition. Los Angeles: SilmanJames Press.

Truby, J. (2007). The Anatomy of Story: 22 Steps to Becoming a Master Storyteller. New York: Faber and Faber, Inc.

Upton, B. (2015). The Aesthetic of Play. Cambridge: MIT Press.

Wendt, T. (2017). Persistent Fools: Cunning Intelligence and the Politics of Design. Lexington: Thomas Wendt.

\section{Cómo citar este artículo en bibliografías - How to cite this article in bibliographies / references:}

DENA, C (2018): "How Creative Processes Are Adapting To Change The World". En Revista de la Asociación Española de Investigación de la Comunicación, vol. 5, número 9, pp. 8-16. 